\title{
Reflexiones en torno al estado actual de la ciencia económica
} Benjamín García Páez*

* Profesor de la Facultad de Economía, UNAM.

A raíz de la crisis financiera global 2008, hay la percepción generalizada de que los economistas librecambistas que han dominado al mundo en las cuatro últimas décadas, han fracasado en la gestión de la economía. Aunque parroquial, tal explicación no está exenta de razón. Los economistas, en general, no somos del todo inocentes en la gestación de la crisis y ello explica porque desde el seno de los propios centros de estudios de economía se exijan mayor apertura y pluralidad en la enseńanza de la economía

En la medida que el proceso de ajuste de los planes de estudio ha sido parsimonioso y de que parece que el mundo ha perdonado no sólo a banqueros, reguladores y gobernantes responsables de la reciente crisis financiera y económica, sino también a los economistas que con sus hipótesis de los mercados financieros eficientes contribuyeron a incubarla, éstos últimos continúan aconsejando a los gobiernos del mundo sobre qué hacer para la recuperación económica; las presentes notas se proponen suscitar el debate entre los economistas mexicanos sobre nuestra profesión $y$, en esa perspectiva, galvanizar el proceso de reforma de la curricula en la Facultad de Economía de la UNAM.

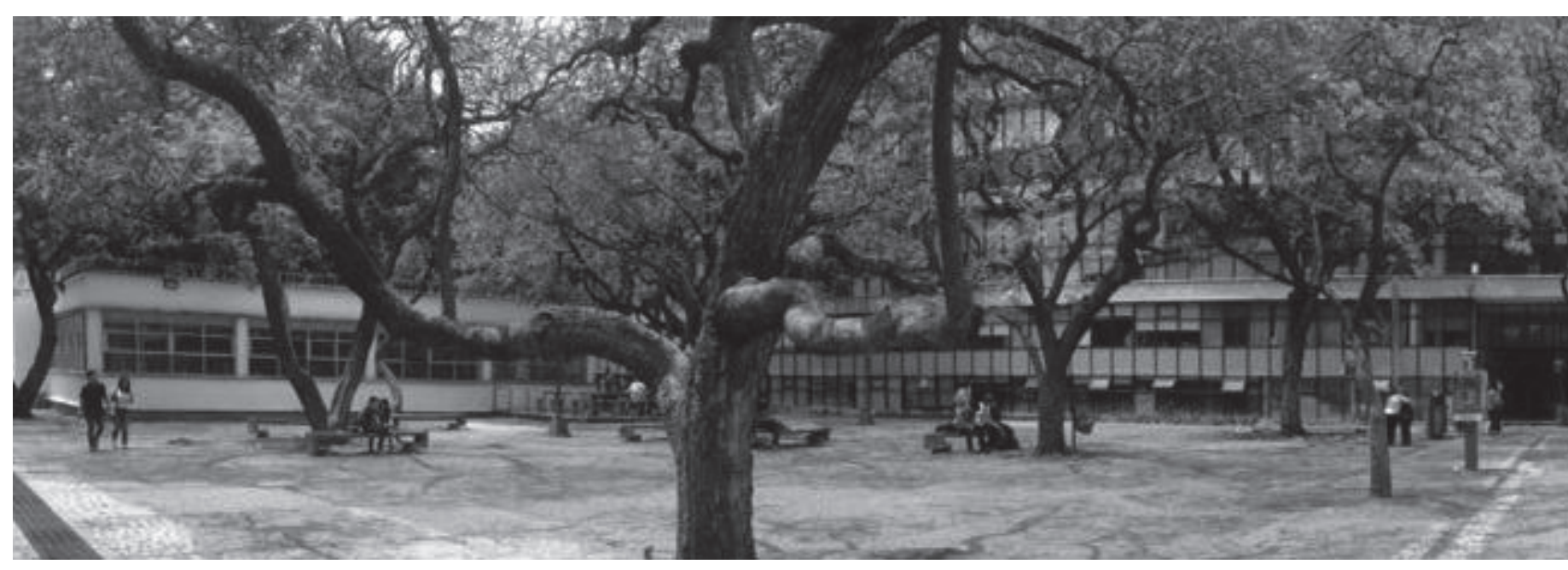

ECONOMÍA INFORMA | 406 | SEPTIEMBRE-OCTUBRE 2017 | 
Benjamín García Páez |

Reflexiones en torno al estado actual de la ciencia económica

I

Antes de la gran crisis (2008), había tácitamente una especie de complacencia tanto entre estudiantes como entre profesores en considerar a la Economía como un enclave intelectual en el que, por un lado, había sólo una alternativa en la que podía ser enseñada, la neoclásica ${ }^{1}$ y, por otro lado, que muy poco podía ser aprendido de psicología, filosofía o cualquier otra disciplina de las ciencias sociales en la explicación y predicción de la cambiante función de los agentes económicos. Sin embargo, después de la crisis, quedaron evidenciadas las escasas posibilidades de poder ayudar a los estudiantes a entender eventos del mundo real. ${ }^{2}$

1 Tony Lawson afirma que "Hace más de un siglo, Thorten Veblen introdujo el término "neoclásica" en Economía a fin de caracterizar un escuela de pensamiento específica. Actualmente, el termino permea el discurso económico, y se emplea para denotar un amplio rango de teorías sustantivas y posiciones de política" ("What is this 'school' called noeclassical economics", Cambridge Journal of Economics 2013, 37, 947-983.

2 La bancarrota de Lehman Brothers había dejado chocados a los mercados financieros y casi ninguna universidad ofreció ayuda para entender porque la falla de un solo banco de inversión en los Estados Unidos
Fueron principalmente-aunque no exclusivamente-, ${ }^{3}$ organizaciones estudiantiles, entre ellas Rethinking Economics (Estados Unidos), Peps-Economie (Francia), Post-crash Economics Society (Reino Unido), International Student Initiative for Economic Pluralism (17 países, principalmente de la OECD), entre otras), las que demandaron una reforma de los planes de estudio para así disponer de una curricula relevante que reflejara diferentes enfoques que permitieran a estudiosos y practicantes de nuestra disciplina evitar errores de política en la prevención y tratamiento de las crisis, económicas y financieras, e incorporara temáticas tales como las de la desigualdad y las consecuencias económicas del cambio climático.

Es decir, los estudiantes demandan acabar con el aislamiento de nuestra disciplina del debate público, que los profesores desechemos

había podido causar un pandemónium en el sistema financiero mundial.

3 Grupos de profesores en ciertas universidades también expresaron la necesidad de una curricula más relevante que reflejara diferentes enfoques y prestara más atención a lo que sucede en el mundo real externo. Inclusive algunos funcionarios públicos y hombres prácticos hicieron su reclamo en ese mismo sentido.

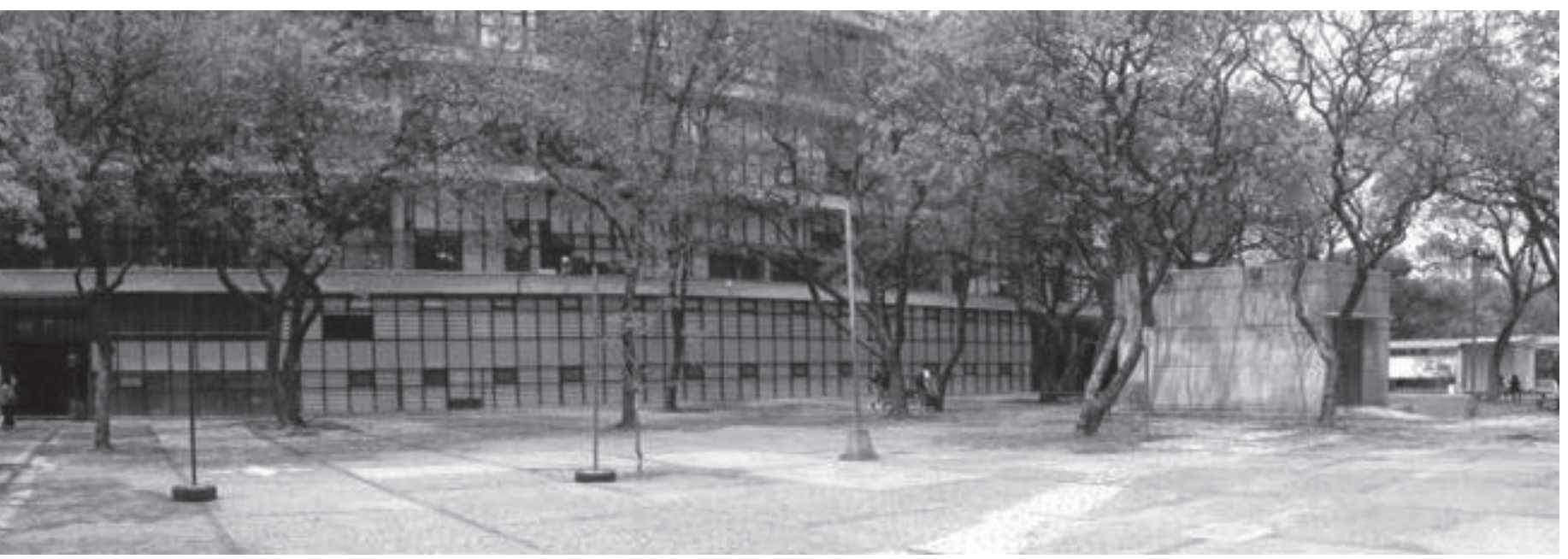


una sola forma de hacer análisis económico y que huya más discusión de teorías alternativas y métodos. Entre los pronunciamientos estudiantiles más provocativos estuvieron los siguientes: "no solo queremos prepararnos para desempeñar un empleo, sino que deseamos cursos para comprender los grandes problemas de economía"; "la mayoría de los modelos económicos que se nos enseñan consideran solo un objetivo: ganancia"; "hay poca consideración a temas como sostenibilidad o equidad"; "la Universidad necesita enseñarnos a desempeñar un empleo, pero primero necesitamos asegurarnos que a las personas a que le destinan grandes montos de capital sean conscientes de los que están haciendo".

Una estudiante, por ejemplo, declaró que su interés por estudiar economía en la Universidad de Mannheim, Alemania, había sido incentivado por entender el problema de la desigualdad -el tópico Thomas Piketty en su libro Capital in the 21st Century-, pero que se sentía decepcionada no solo porque el tema que deseaba discutir no eran de interés en esa universidad, sino porque además no había pensamiento crítico prácticamente sobre nada. ${ }^{4}$

Lo cierto es que aunque ya existían inconformidades con la curricula de Economía, la gran de 2008 fue una especie de catalizador porque, además, con ella habían quedado maltrechos algunos economistas que argumentaban se habían resuelto los problemas más grandes del mundo. De hecho, las políticas adscritas a la economía neoclásica dominante contribuyeron decisivamente a la denominada Gran Moderación -como se llamó a la era de estabilidad y prosperidad en las décadas previas a la crisis-.

En resumen, el consenso giraba en torno a que ha sido una miopía considerar sólo una escuela de pensamiento económico. Como se-

4 Claire Jones, "Economics: Change of course." May 16, 2014- ñalara Louison Cahen-Fourot, un miembro del Peps-Economie, "No somos anti-neoclásicos, anti-matemáticas. Lo único que creemos es que la economía neoclásica es parte de algo más grande." ${ }^{5}$ Enseñar un rango más amplio de enfoques es esencial si es que realmente las nuevas generaciones, particularmente académicos, funcionarios gubernamentales y empresarios; desean tanto evitar errores de política incurridos en el estallido y durante las crisis, como en la etapa del combate a patologías macroeconómicas tales como desigualdad y las consecuencias económicas del cambio climático, por ejemplo.

\section{II}

El pronunciamiento de Eric Beinhocker director del Oxford Martin School, dependiente del Institute for New Economic Thinking, ${ }^{6}$ en el sentido de que "El mundo ha cambiado mucho. La Economía ha cambiado también bastante, pero la curricula del economista no lo ha hecho", encapsula de forma apropiada la discusión anterior sobre el imperativo de rediseñar los planes de estudio de nuestra disciplina. Pero el hecho es que casi a nueve años del colapso de Lehman Brothers, los cursos universitarios estándar de Economía hayan cambiado muy poco, preocupa. Mientras que aun en los 1980s era común para los estudiantes elegir módulos en Historia Económica y Economía Pública; en las últimas tres décadas, los cursos de Economía han estado dominados por métodos cuantitativos fincados en hipótesis de la escuela neoclásica. ${ }^{7}$

5 The $\mathrm{BBC}$, What happens with the dismal science? January 2009.

6 Organización fundada por Jorge Soros en 2009.

7 En Francia, por ejemplo, sólo el 1.7 por ciento de los módulos en las universidades cubrían Historia Económica y había un solo curso dedicado a la Epistemología de la economía. 
En el proceso de restructuración de los planes de estudio de Economía, es necesario el examen de algunas experiencias para tomarlas como parámetros de referencia. En este sentido veamos cuál ha sido la respuesta de un centro de estudios que no es marginal sino quizá uno de los lugares donde mejor docencia e investigación económica se hace en el mundo, la Facultad de Economía y Ciencias Políticas de Cambridge University, Inglaterra ${ }^{8}$ a los retos de la dinámica económica actual desde antes incluso del descontento de las organizaciones estudiantiles arriba referido. Un apretado resumen de los rasgos distintivos de tal respuesta y el sustento teórico asociado, es como sigue:

\section{No puede haber una sola manera "correcta" de hacer Economía}

Actualmente se distinguen nueve escuelas de economía (considerando sólo las más grandes), entre las que hay tres variantes de economía de libre mercado: Clásica, Neoclásica y Austriaca. Todas ellas postulan diferentes supuestos políticos y éticos, enfatizan diferentes cosas (por ejemplo, producción o intercambio), y sostienen diferentes teorías sobre como las economías cambian en el largo plazo. Es importante, por lo tanto, aprender sobre diferentes tipos de teorías económicas y sus relativas fortalezas y debilidades porque la realidad es compleja y, por lo tanto, no podemos entenderla en forma plena cuando nos adherimos a un sólo enfoque, sino que se requiere de un rango diverso de teorías.

8 La Facultad de Economía Ciencias Políticas no imparte cursos a nivel de posgrado, Maestría y Doctorado, pero conforme la nueva reforma académica participa en los cambios de curricula en el sistema de los colegios que imparten Economía en pregrado o en aquellos que la tienen como un componente principal de diversas licenciaturas que ofertan.
Para tratar con los problemas económicos actuales necesitamos diferentes enfoques económicos para diferentes problemáticas.

\section{No todas las ideas neoclásicas son inútiles}

El enfoque neoclásico puede proveernos de diferentes herramientas para analizar problemas dentro de una cierta estructura dada, pero no es muy eficiente para entender las instituciones, tecnologías, política e ideas que definen tal estructura y como ésta ha evolucionado en el tiempo.

Hayek, por ejemplo, es muy diferente de la Escuela Neoclásica, aun cuando algunos economistas neoclásicos lo ubican al mismo nivel que a Friedman, debido a que fue uno de los partidarios más influyentes del libre mercado. A diferencia de los economistas neoclásicos, sin embargo, Hayek no toma como dado el orden sociopolítico subyacente en la relación mercantil, sino que subraya la naturaleza política de nuestra vida económica. Este es un gran contraste al punto de vista neoclásico que considera que economía y política deberían ser separadas. De hecho si uno lee Individualismo y Orden Económico (Hayek 1948) ${ }^{9}$ se constata que Hayek es muy crítico de la economía neoclásica.

Al otro extremo del espectro político está Carlos Marx. Con el colapso del comunismo, se tendió a juzgar a Marx como un autor irrelevante. Esto es incorrecto. Abstrayéndonos de su visión utópica de socialismo y su teoría valor trabajo, su entendimiento del capitalismo fue superior en muchas formas a aquellos que se autodefinen defensores cruzados del capitalismo. Por ejemplo, cuando los librecambistas estaban principalmente contra las empresas de responsabilidad limitada, Marx las vio como

9 F.A. Hayek (1948), Individualism and Economic Order, The Chicago University Press. 


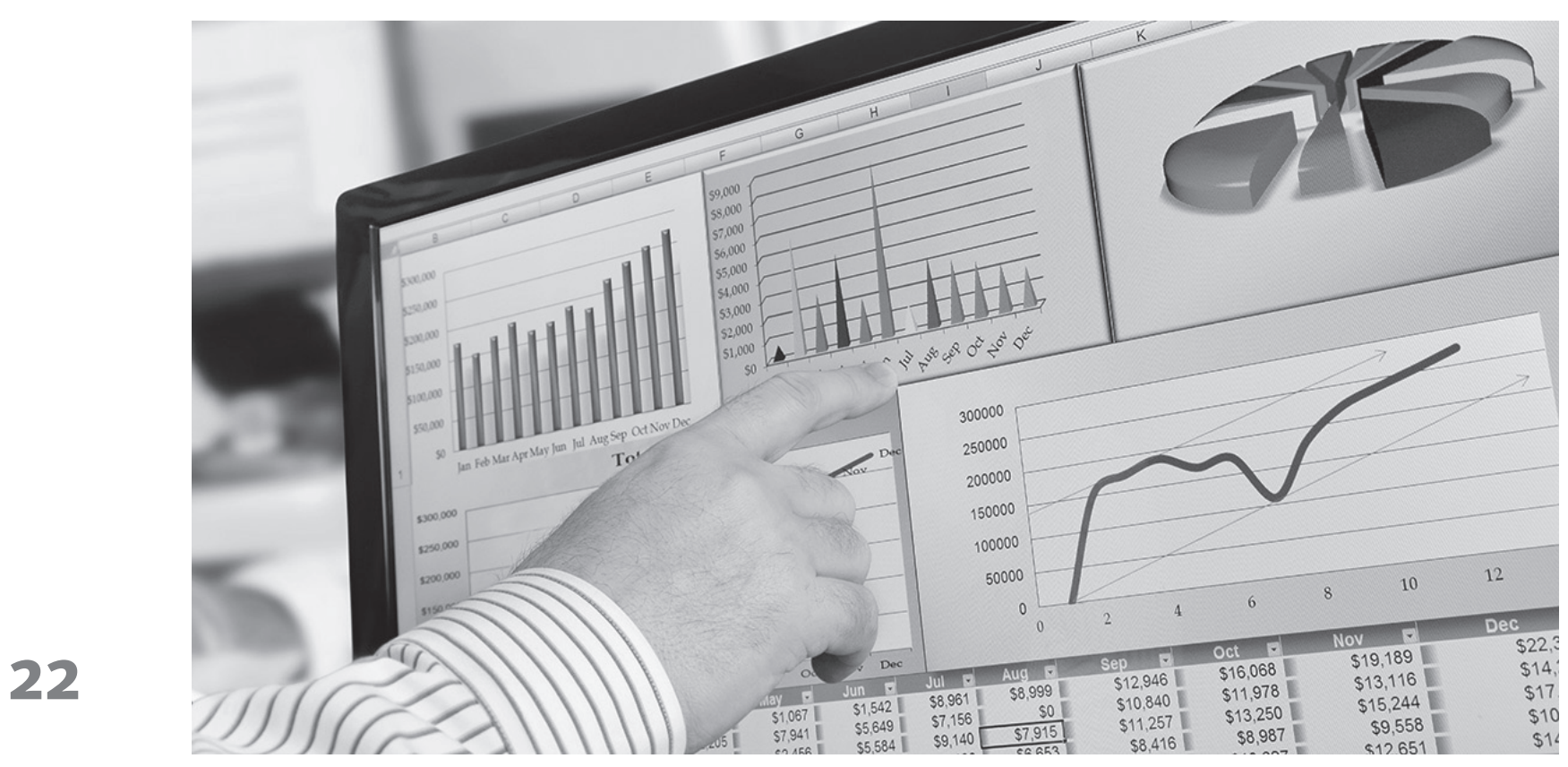

una institución que llevaría al capitalismo a otro plano, hacia el socialismo. Marx también entendió la centralidad de la interacción entre tecnologías (fuerzas de la producción) e instituciones (relaciones de producción), las cuales otras escuelas de pensamiento económico apenas recientemente entienden.

También Joseph Schumpeter, Nicholas Kaldor, Albert Hirshman y Friedrich List fueron visionarios en la evolución de largo plazo del capitalismo. Sostuvieron diferentes enfoques entre si y se interesaron en diferentes aspectos del capitalismo, pero todos ellos han influido en el desarrollo teórico y en la praxis de nuestra disciplina en ámbitos tales como los procesos de evolución tecnológica y creación de riqueza y las luchas políticas en torno a esos procesos. Un ejemplo de las cosas por explorar es el legado de Herbert Simon quien después de hacer investigación fundamental en economía, investigación de operaciones, psicología, administración pública, ciencia política e inteligencia artificial, llego a entender como las personas pensamos y tomamos decisiones y exploró en profundidad y de diversas maneras las implicaciones de este entendimiento para el diseño de organizaciones e instituciones sociales. ${ }^{10}$

Asimismo, en el entendimiento de las crisis financieras, particularmente la asiática (1997) y la mundial (2008), los desarrollos teóricos de John Mynard Keynes, Hyman Minsky y Charles Kindleberger han sido sumamente útiles para explicar -aunque sea expost por parte nuestra-, a las crisis.

\section{No todos los economistas neoclásicos}

son economistas de libre mercado

Mediante sus desarrollos en economía del bienestar pero también en globalización, desarrollo económico y crisis financieras, economistas neoclásicos tales como William Baumol, David Romer, Amartya Sen y Jo-

10 Algunos economistas neoclásicos han adoptado la noción de "racionalidad limitada" (bounded rationality), pero desafortunadamente solo en su versión sanitada, porque esta fundamentalmente en conflicto con el formato de optimización racional de la economía neoclásica. 
seph Stiglitz han influido decisivamente en el pensamiento económico moderno. En general, pensamiento económico que atraviesa diferentes escuelas -Marxista, Neoclásica e Institucionalista-, con diferentes e innovadores enfoques sobre desarrollo económico, nos han enseñado a investigar lo que está encarnado en la realidad.

\section{Un arreglo consensuado y dinámico entre Neoclásicos y Post-keynesianos}

La teoría económica neoclásica dominante puede ser poderosa cuando analizamos problemas bien especificados en un contexto en que tecnologías y política son estables, pero necesitamos los enfoques Austriaco y Keynesiano a fin de tener un mejor manejo con situaciones caracterizadas por la incertidumbre y la inestabilidad. Deberíamos usar más los enfoques institucionalista $\mathrm{y}$ conductual, si queremos proponer soluciones robustas sobre reformas sistémicas, sean sobre finanzas o sobre el sistema de bienestar. Considerando reanimar el dinamismo económico en el largo plazo, tenemos que aprender más de las corrientes Schumpeterianas, desarrollistas, clásica, y de las escuelas Marxianas.

\section{III}

La restructuración de la curricula en la Facultad de Economía de la UnAm cuya vigencia data desde 1994, es una necesidad incontestable e impostergable. Dadas las premisas expuestas, su transformación pareciera ser una tarea relativamente manejable ya que no se tendría porque escarmentar todo en cabeza propia pues los reformadores disponen de diversos parámetros de referencias, válidos y exitosos, como aquel arriba mencionado de Cambridge University. Sin embargo, el proceso se complejiza al menos por las dos siguientes razones:
Primero, dado patrón de desarrollo institucional de las universidades públicas en México, las reformas no se dan como parte de un plan estratégico. Aun cuando la reforma 1994 constituyó un cambio significativo en relación a un plan de estudios marcadamente obsoleto y que plasma mejoras internamente inducidas, su orientación pareció responder más a presiones externas por enseñar un solo tipo de Economía, la neoclásica, porque se creyó que ello nos asemejaría a otros centros de enseñanza de la Economía del país que privilegiaban el estudio de la estabilidad de mercados específicos -bienes y servicios, trabajo, capital-, e instrumentos -tasa de rendimiento, margen de beneficio, precios relativos, etcétera-, en vez de hacer girar la formación académica de sus estudiantes en torno al problema del crecimiento $\mathrm{y}$ de plantearse grandes objetivos nacionales como la elevación de los niveles de producto, empleo bien remunerado y del bienestar social como objetivos de política económica. Por supuesto, sin suprimir el estudio de las primeras problemáticas del todo.

Más aún, la reforma de curricula 1994 no sólo estuvo antecedida por la hegemonía de la corriente principal (mainstream) que había recientemente accedido al poder político de los países en la mayor parte del mundo, México, entre ellos; sino también del activismo ideológico de economistas de libre mercado que creían, y lo externalizaban a otras personas, que la economía era una ciencia aséptica, como la Física o la Química, sin soporte de la política o la ética, no obstante que la Economía, y el campo de la Economía, se determina por juicios éticos y políticos, el mercado mismo es un constructo político, más que un orden natural que debería ser atemperado por la intervención política.

Considero que en la adecuación del plan de estudios 1994, sucumbimos parcialmente 
ante esos embates de la guerra ideológica contra el Estado y la pretendida supremacía del mercado en la asignación de recursos, quedándonos no con el plan de estudios necesario y deseable en esas circunstancias, sino aquel políticamente posible. ${ }^{11}$

\section{0 obstante las restric- ciones y desafíos an- teriores, el proceso de reforma académica de la Facul-}

tiene que darse, bien y pronto, aprovechando condiciones

mejores que aquellas prevalecientes en 1994 [...] hoy se cuenta con una planta docente intelectualmente madura en todas las áreas académicas que la conforman

Y, segundo. La unAm es la universidad de la nación y si alguna de las facultades permite constatarlo de manera fehaciente, esa es la de Economía. Es esperado que el nuevo modelo curricular al que lleguemos, servirá de parámetro de referencia a otras escuelas de econo-

11 Recuerdo la llegada de cierta correspondencia enviada a la División de Estudios de Posgrado de la Facultad de Economía, desde la Presidencia de la Republica, direccionada no como tal, sino que creo deliberadamente, remitida a la "Coordinación de Estudios de Ideología". mía del país, particularmente aquellas pertenecientes a instituciones de educación superior de naturaleza pública estatal. ${ }^{12}$ Esto hace que la actual reforma del plan de estudios contemple otra dimensión con dos aristas: por un lado, se eleva nuestra responsabilidad intelectual ya que, es posible, el rediseño a nuestro plan de estudios se replique en otros centros de estudio pero, por otro lado, al imperativo de que la reforma se centre en los requerimientos específicos de nuestra facultad para que ésta cumpla sus funciones sustantivas de manera técnicamente solvente y cabal. Otrora, hemos tratado de liderar un proceso de homologación de planes de estudio pero el esfuerzo se ha visto frustrado no sólo por la propensión nuestra, los economistas, a discrepar gremialmente, sino a las anclas de aquellas universidades que luchan denodadamente por sostener planes de estudio acentuadamente obsoletos como suele pasar en escuelas y facultades de Economía de algunas entidades federativas en el país.

\section{IV}

No obstante las restricciones y desafíos anteriores, el proceso de reforma académica de la Facultad de Economía de la UnAm tiene que darse, bien y pronto, aprovechando condiciones mejores que aquellas prevalecientes en 1994. Aparte de una infraestructura física fortalecida, nuevas tecnologías educativas y la disposición de un modelo moderno de organización escolar, hoy se cuenta con una planta docente intelectualmente madura en todas las áreas académicas que la conforman. Por supuesto, el proceso requerirá también de la concurrencia de los "espiritus animales", parafraseando

12 Incluso, el plan de estudios de la Facultad de Economía de la UNAM se utiliza como referente en procesos de renovación de curricula en otros países de América Latina. 
U

na de las tácticas pedagógicas más recientes en la enseñanza de nuestra disciplina, es alentar más la interacción estudiantil, dentro y hacia el exterior de los salones de clase, porque ello estimula el estudio y la discusión de ideas

a Keynes quien aseguraba que la presencia de ellos, era clave para el éxito de las políticas públicas y de otras acciones, porque infundían la confianza necesaria en los procesos.

Con la convicción de que el flujo de ideas contribuye a mejorar la propuesta de reforma del plan de estudio del área a la que me adscribo en el programa de licenciatura: Teoría Económica y Economía Publica; quisiera ir más allá de sugerir la obvia necesidad de acumular una mayor "inteligencia del mercado" vía revisión de diversos programas académicos en México y en el mundo -aspectos que de alguna manera han sido atendidos ya por los reformadores-, para ponderar algunos aspectos transversales, no necesariamente en orden prelativo, y que pudieran servir preventivamente de lineamientos generales:

\section{Evitar la formación de Economistas autistas}

Una de las tácticas pedagógicas más recientes en la enseńanza de nuestra disciplina, es alentar más la interacción estudiantil, dentro y hacia el exterior de los salones de clase, porque ello estimula el estudio, la discusión de ideas y la creatividad en la formulación de opciones de política, micro y macroeconómica. Ade- más esto se ha vuelto irrefrenable con el uso intensivo de las redes sociales. Bien, si queremos una formación académica solida, confiable y completa que vuelva visibles a nuestros estudiantes, tenemos que contribuir al manejo de un lenguaje común que la apalanque.

Recordemos que, en el fondo, la Economía es un campo de indagación (un método de cuestionar para explicar fenómenos y procesos y, eventualmente, predecir su evolución futura), y una manera de pensar.

\section{Evitar la "Parálisis del Ciempiés"13}

Quizás tratando de suavizar, o alejarse de, la micro-fundamentación de la macroeconomía, se tiende a desvanecer la conveniencia analítica probada de mantener la direccionalidad de la enseñanza de la teoría económica a través del ciclo: micro-macro-equilibro general que además, da espacio para incorporar nuevas vertientes como Economía de la Felicidad, Economía Conductual, Economía Ambiental y Ecológica, Economía de la Salud, Economía de la Complejidad, etcétera, con el argumento de que en sus orígenes, nuestra disciplina concebía a la economía como un todo. Esto constituye un atavismo pedagógico. Todas las ciencias han surgido abordando de manera entera su objeto de estudio y son evolutivas. Bajo esa línea de argumentación pudiéramos también decir que como la Economía inicia siendo una rama de la filosofía moral, para aprenderla habría que plasmar en el programa de estudios la

13 Parábola citada por Paul Krugman en su artículo "A country is not a company", Harvard Business Review, January-February issue, 1996, para recordarnos, primero, no crear ciempiés artificiales $y$, segundo, para no incurrir en el riesgo de cuando le pidamos que piense en cómo coordina los ciempiés para caminar, el ciempiés quede paralizado. 
epistemología de nuestros principios fundadores. Evidentemente, esto también sería un absurdo. Esto último no es para negar que la clase de personas que postula la Economía, a diferencia de las partículas y las fuerzas estudiadas por los físicos y químicos, mantienen puntos de vista políticos y morales. El cambio de plan de estudios en nuestra facultad tiene que inscribirse en un proceso de transición, rápida pero de manera consistente y coherente.

\section{El perfil de egreso de nuestro tiene que ser} uno competitivo no el de un aprendiz discapacitado

En la formación de recursos humanos, desarrollamos conocimientos y habilidades acumuladas, a través de diversas fuentes, por parte de los jóvenes que emprenden sus estudios de Economía - por cierto, fundamentos matizados por la economía convencional-, y sobre ello edificamos nuevos conocimientos y habilidades pero, al punto de egreso, tenemos el compromiso ético de que nuestros profesionales sean, técnica y humanísticamente solventes para competir y desempeńar un empleo, o para continuar un proyecto académico de posgrado.

En el llamado a una mayor apertura y pluralidad en la enseńanza de la Economía después de 2008, no sólo hubo académicos, como se dijo, sino también empleadores que se han vuelto más críticos en reclamar la calidad de los "productos" que contratan y egresan tanto de los programas de licenciatura como de posgrado en Economía, porque cabe la posibilidad de encontrar, por ejemplo, profesionales altamente entrenados en Matemáticas y Estadística, pero muy estrechos en perspectiva teórica y muy ignorantes sobre cómo se comportan realmente los agentes económicos y en cómo funcionan las economías. Es pertinente citar aquí a Edmund Phelps (Premio Nobel en Economía 2006) quién considera un "punto ciego" de la disciplina el no aquilatar en su enseñanza el valor de la inclusión que él define como "el deseo de los estudiosos de la Economía por hacer algo con sus vidas más allá de consumir bienes, o de tener tiempo libre, y así poder participar en la comunidad en la cual interactúan y se desarrollan y que tal falencia es grave debido a que una buena parte de buena vida acontece en la actividad económica, sobre todo en el lugar de trabajo y en el esfuerzo creativo inherente a empleos psicológicamente gratificantes."14

\section{No auto-restringirnos con un número limitado de hipótesis de teoría económica en el análisis empírico}

Es consenso casi generalizado que las hipótesis de teoría económica de carácter neoclásico han sido más profusamente sometidas al trabajo empírico, en la econometría, por ejemplo; que aquellas de persuasión pos-keynesiana que han sido menos trabajadas, en virtud de la limitada cantidad, cobertura temática, débil rigor e integralidad de las hipótesis hasta hoy desarrolladas, no obstante que se trabaja intensamente en ello.

\section{No pausarnos entre las diferentes áreas académicas}

A riesgo de ser incisivos, necesitamos de un proceso integral de diseño e instrumentación de la deseable nueva curricula, porque de otra forma como en la parábola del ciempiés, podríamos quedarnos paralizados. La

14 Edmund S. Phelps, "The importance of Inclusion and the power of job subsidies to increase it", paper conference: COM/DEELSA/ELSA/ECO/CPE/ (99)66. 
operativización temática y ejercicios no sólo en métodos cuantitativos sino en áreas tales como: economía de la empresa, historia económica, pensamiento económico, economía internacional, economía política, entre otras, tienen como componente principal a la teórica económica neoclásica. Va a requerir un esfuerzo deliberado y explícito hacia el interior de la Facultad de Economía para homogenizar un aprendizaje plural en la propia planta docente.

\section{Desmitificación del aprendizaje de la Economía}

En una etapa en que el ciudadano promedio necesita incorporar Economía a sus conocimientos y habilidades cognitivas, estamos urgidos de desmitificar a la Economía, es decir, de volverla más fácil de entender porque, como afirma Chang, ${ }^{15}$ esa es la única garantía de tener buenas políticas económicas. Además, formatos ininteligibles de comunicar las ideas económicas estimulan la crítica profesional errónea e interesada, particularmente desde el ámbito de los políticos. El punto es que muchas personas se niegan a aprender economía porque tienen la percepción generalizada de que es una disciplina muy técnica que está más allá del alcance de no especialistas. Los economistas debemos acabar con el temor a la Economía pues complejizar su entendimiento ha reducido la habilidad de los ciudadanos para incidir sobre la hechura de políticas económicas, haciéndolo crecientemente sentirse desesperanzados y desinteresados en políticas democráticas.

15 Chang, Ha-Joon, opus cit.
Martin Wolf afirma que también el malestar sobre cómo se enseña Economía ha hecho perder la confianza del público en la aceptada sabiduría que se tenía en los hacedores de política económica y que, por lo tanto, en los procesos de reforma curriculares no sólo se deben incorporar nuevas ideas y técnicas para volver a nuestra disciplina más efectiva en el análisis de los desafíos intelectuales y de política contemporáneos, sino también permitir a los estudiantes no sólo a desempeñar de manera eficiente sus actividades como empleados o como empresarios, sino también a cumplir un mejor papel como ciudadanos toda vez que en esa trayectoria también se coadyuva a que las personas versadas en los conceptos económicos básicos, tomen sentido de los debates sobre crecimiento, impuestos, política monetaria y desarrollo económico, desigualdad, etcétera. ${ }^{16}$

\section{Una curricula flexible con perspectiva de largo plazo}

Bajo el enfoque de la escuela neoclásica, se han formado más de dos generaciones de economistas en el mundo. Si estratégicamente se decidiera que la heterodoxia se convierta en la nueva ortodoxia, parafraseando a Harry Johnson; ${ }^{17}$ debemos recordar que la gradual instalación de un enfoque heterodoxo dominante, demanda que alumnos y profesores comencemos a entrenar-

16 Martin Wolf, "Students weigh the value of new economics course", Financial Times, April 10, 2015.

17 Harry Johnson, "Revolution and Counter-Revolution in Economics: From Lord Keynes to Milton Friedman", en Encounter review, 1974. Conforme a Johnson, la Economía disciplinariamente avanza a través de revoluciones y contrarrevoluciones, es decir, del debate entre una sabiduría ortodoxa dominante y un enfoque heterodoxo desafiante pero que, eventualmente con el triunfo de este último, se vuelve la nueva ortodoxia $y$, por lo tanto, expuesta a futuros ataques de la emergente heterodoxia. 
nos, entre otras cosas, en matemáticas dinámicas y ecuaciones diferenciales ordinarias no lineales. Es decir, bajo cualquier circunstancia, nuestra disciplina continuará seguirá siendo técnica por excelencia si nos adscribimos al método científico en la investigación económica y queremos usar la mejor manera consolidar el pilar central de nuestra carrera: la teoría económica.

\section{Un granito de pragmatismo pudiera funcionar en nuestra reforma académica}

Es evidente y entendible la generalizada insatisfacción estudiantil sobre cómo se enseña nuestra disciplina y de que tiene que incluirse a la economía heterodoxa en el core de los planes curriculares de licenciatura y posgrado. Pero es responsabilidad intelectual de todos los que hacemos Economía desde la UNAM, comprender: a) que el valor cognitivo para los estudiantes y los investigadores no se obtiene como en el campo de la Filosofía o de la Crítica Literaria el cual subyace y se acumula en el debate mismo, sino que en Economía reside en la adquisición de un cuerpo de conocimientos prácticos, relevantes y socialmente útiles; ${ }^{18}$ b) que es útil exponer a los estudiantes a alternativas heterodoxas a la economía ortodoxa pero que pluralismo académico implica la exposición de ellos a paradigmas económicos alternativos competitivos, y a veces complementarios, entre sí $y,{ }^{19}$ c) que

18 Robert Skidelsky, biógrafo de JM Keynes, nos recuerda que la aspiración del Maestro era que su profesión, la nuestra también, pudiera algún día tener el estatus de los odontólogos, "Personas competentes y humildes".

19 Precisamente porque los economistas propendemos a olvidar que "pluralismo" significa, es que muchos convenimos que Jean Tirole (Premio Nobel 2014), estuvo en lo correcto al persuadir al Ministro de Educación de su país no añadir un capitulo distintivo de el enfoque crítico en educación económica supone el dominio del otro enfoque, o de los otros, si es que aspiramos a cuestionarlos con talento.

\section{El papel del(a) profesor(a) es crucial en la diferenciación del tipo de economista que se forma}

Para que la reforma de la educación económica funcione, es determinante el compromiso y la pertenencia institucional de lo(a)s docentes. Lo anterior no sólo por la instrumentación que el rediseńo mismo de la curricula misma reclama: participación e inclusión, entre otros aspectos, sino por la convicción de la argamasa del(a) egresado(a) continuará siendo matizada por la función docente y ello demanda la capacidad docente para formar al alumno(a).

Por ejemplo, el problema no es tanto con las hipótesis que invoca la eficiencia de los mercados, sino con la superestructura conceptual en la cual se finca -un mundo de agentes racionales imbuidos con expectativas racionales- persiguiendo un estado de equilibrio (término prestado de la Física), a través del comercio con otros agentes racionales movidos por expectativas racionales similares. Si no hay profesores que comuniquemos que tal hipótesis debe ser entendida como una tendencia, no como una ley y que la palabra racional se utiliza para describir agentes y expectativas con un significado muy diferente con respecto a su uso ordinario pero que aun así, el uso del

"Economía Heterodoxa" en el Consejo Nacional de Universidades que determina quien está calificado para enseñar en las universidades. "Es inconcebible para mí, escribió Tirole, "que Francia reconozca dos comunidades dentro de la misma disciplina." Creo que en el fondo lo que Tirole quiso decir es que pluralismo científico es apertura mental, no relativismo cognitivo. 


\section{Benjamín García Páez |}

Reflexiones en torno al estado actual de la ciencia económica

término "racionalidad" es irrelevante en un mundo caracterizado por la información imperfecta o, en otro contexto, de que no es posible que los precios de los bienes financieros en cambio permanente configuren un punto de equilibrio dado; entonces tendremos otra tipo de problema en el entendimiento de la compleja realidad económica que trasciende el ámbito estrictamente curricular. ${ }^{20}$

Ciudad Universitaria, UNAM, Cd Mx, Julio 2017.

20 John Kay, "The Nobel committee is muddled on the nature of economics", Financial Times, October 15, 2013.

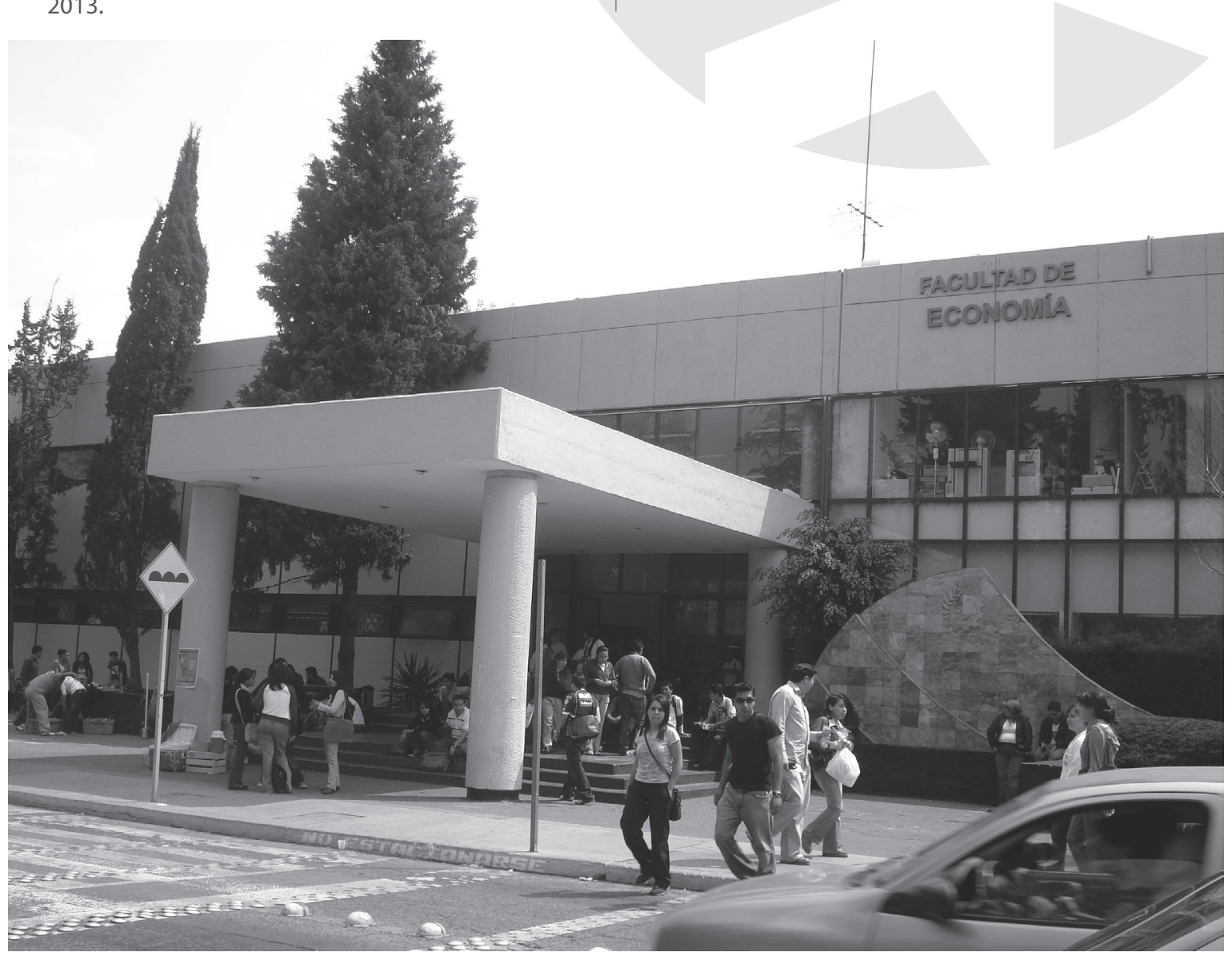

